\title{
Retalho de Rotação Súpero-Medial: Resultados em Três Doentes
}

Superomedial Rotation Flap: Results in Three Patients

Ermelindo Tavares ${ }^{1}$

Autor Correspondente: Ermelindo Tavares [tavares.ermelindo@gmail.com Estrada Carlos Lima Costa, n², Povos, 2600-009 Vila Franca de Xira, Portugal

\section{RESUMO}

INTRODUÇÃO: O retalho de rotação súpero-medial é um retalho cutâneo local, randomizado, e predominantemente de rotação, que permite encerrar defeitos de média e grande dimensão, nas regiões malar súpero-medial e pele palpebral inferior.

MATERIAL E MÉTODOS: Dois homens e uma mulher foram submetidos a exérese alargada de lesões clinicamente sugestivas de carcinoma basocelular da face, sob anestesia local, seguida de reconstrução com retalho de rotação súpero-medial.

RESULTADOS: Não se registaram complicações pós-operatórias imediatas ou tardias. Os resultados funcionais e morfológicos foram aceitáveis. Os doentes não apresentaram recidivas nos 12 meses de seguimento.

DISCUSSÃO: O retalho de rotação súpero-medial é um procedimento simples, realizado em tempo operatório único, sob anestesia local. Constitui uma excelente opção dentre as várias técnicas cirúrgicas reconstrutivas perioculares clássicas. O ectrópio é uma complicação rara.

CONCLUSÃO: O retalho de rotação súpero-medial revelou-se uma opção cirúrgica segura e eficaz nos três casos.

PALAVRAS-CHAVE: Carcinoma Basocelular; Pálpebra; Retalhos Cirúrgicos 


\section{ABSTRACT}

INTRODUCTION: The superomedial rotation flap is a local randomized rotation flap that allows the closure of medium and large surgical defects in the superomedial malar region and the lower cutaneous eyelid.

MATERIAL E METHODS: Two male patients and one female patient were submitted to wide excision of facial basal cell carcinoma, under local anesthesia, followed by superomedial rotation.

RESULTS: There were no postoperative complications. Functional and aesthetic results were acceptable. Patients remain relapse-free at one year.

DISCUSSION: Superomedial rotation is a simple procedure that is performed under local anesthesia in a single surgical period. It is an excellent option to many classical periocular surgical techniques. If well executed ectropion is an uncommon complication.

CONCLUSION: Superomedial rotation was a safe and effective optional procedure in all cases.

KEYWORDS: Carcinoma, Basal Cell; Eyelids; Surgical Flaps

\section{INTRODUÇÃO}

As regiões malar e palpebral inferiores são duas áreas faciais comummente afetadas por cancro cutâneo não melanoma, em particular o carcinoma basocelular (CBC). A cirurgia constitui o tratamento de primeira linha, sendo os seus objetivos fundamentais a excisão completa, seguida de reconstrução, com o propósito da obtenção de um bom resultado morfológico, bem como a manutenção e/ou restituição da função. O tamanho e a profundidade do defeito, a experiência do cirurgião, o tipo histológico do tumor e a presença de cicatrizes locais são alguns dos vários fatores que irão influenciar a escolha do método reconstrutivo mais adequado (encerramento direto, retalho, enxerto ou cicatrização por segunda intenção).

Em 2012, Hussain et al ${ }^{1}$ descreveram uma nova opção para o encerramento dos defeitos cirúrgicos da região malar súpero-medial e pálpebra inferior, que denominaram retalho de rotação súpero-medial (RRSM). Trata-se de uma técnica em que o reservatório da pele geniana é mobilizado superior e medialmente ao longo da prega nasogeniana, com a coadjuvação dum crescente deslizante posicionado na extremidade inferior do retalho. Pretende-se com este trabalho descrever o RRSM, demonstrar os seus resultados em três casos, e discutir os seus aspetos teórico-práticos à luz dos dados publicados na literatura.

\section{MATERIAL E MÉTODOS}

\section{Doentes}

Dois homens (um de 70 e outro de 71 anos) e uma muIher (de 81 anos), caucasianos e com história de exposição crónica à radiação solar foram submetidos à excisão de CBC na região malar súpero-medial direita (caso 1) e esquerda (casos 2 e 3) (Tabela 1 e Fig.s 1 a 3).

\section{Técnica cirúrgica}

O procedimento foi executado sob anestesia local, num único tempo operatório. As neoplasias foram removidas com margens cirúrgicas laterais de 5 mm e profundas até à superfície muscular.

O RRSM foi o método de reconstrução utilizado no encerramento dos defeitos. Este foi delineado e dissecado de acordo com as seguintes orientações (Fig. 4):

1. Incisão circular ou elíptica da neoplasia (Fig.s 1b e 2b);

2. Incisão do retalho ao longo da prega nasogeniana (Fig.s 1b, 1c, 2b, 2c e 3b);

3. Incisão elíptica ou semi-elíptica do crescente (Fig.s 1c, $2 c$ e 3b) de tal modo que sejam relativamente respeitadas as seguintes relações métricas: a distância entre a base do defeito (ponto B, Fig. 4) e o ponto de início do crescente (ponto C, Fig. 4) é igual ou superior à altura do defeito (distância AB, Fig. 4), ou seja, começar o ponto superior do crescente a uma distância mínima equivalente à altura do defeito; a diferença (em comprimentos) entre as duas faces do crescente é, no mínimo, igual à altura do defeito; a distância (em comprimentos) das duas faces do retalho [linha vermelha (AD) e linha verde (BE), Fig. 4] é idêntica;

4. Descolamento cutâneo amplo e cuidadoso ao nível do tecido adiposo (Fig. 3c);

5. Ancoragem da ponta do retalho ao periósteo periorbitário;

6. Sutura do retalho da extremidade inferior para o superior (Fig.s 1d, 2d e 3d); 

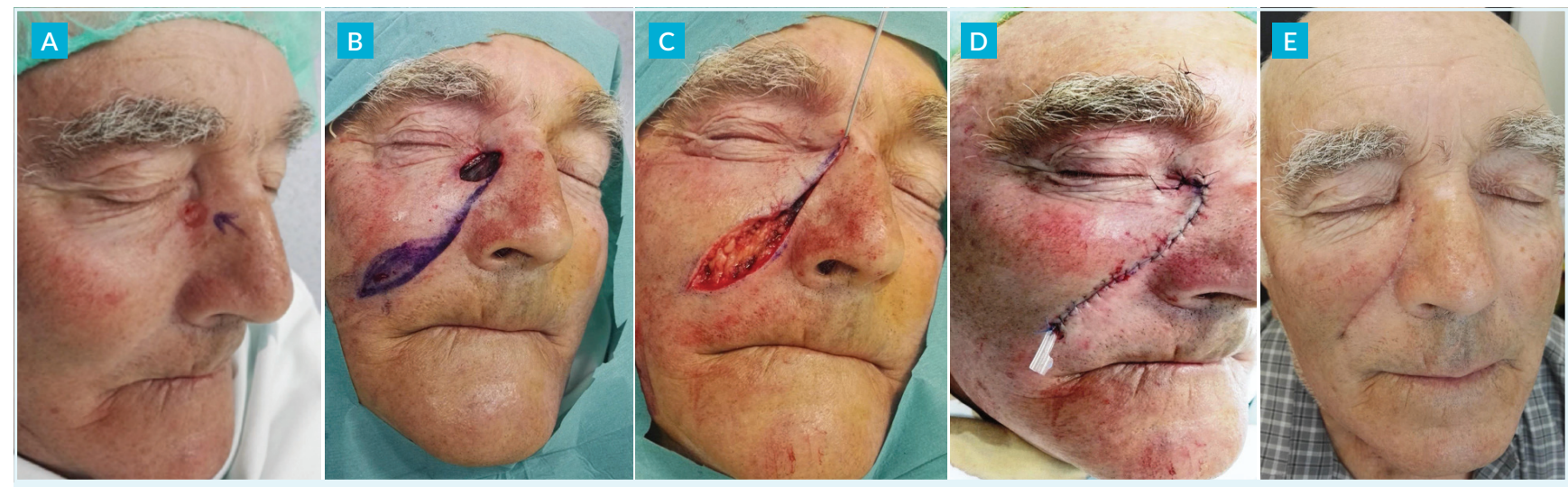

FIGURA 1. Carcinoma basocelular na região malar súpero-medial e pele palpebral ínfero-medial direito (a). Retalho de rotação súpero-medial delineado e dissecado ao longo da prega nasogeniana (b e c); distância entre o crescente e o defeito é superior à altura deste último (b). Resultado imediato com pele palpebral adaptada paralelamente às linhas de tensão (d). Bom resultado estético e funcional após seis semanas, sem ectrópio cicatricial (e).

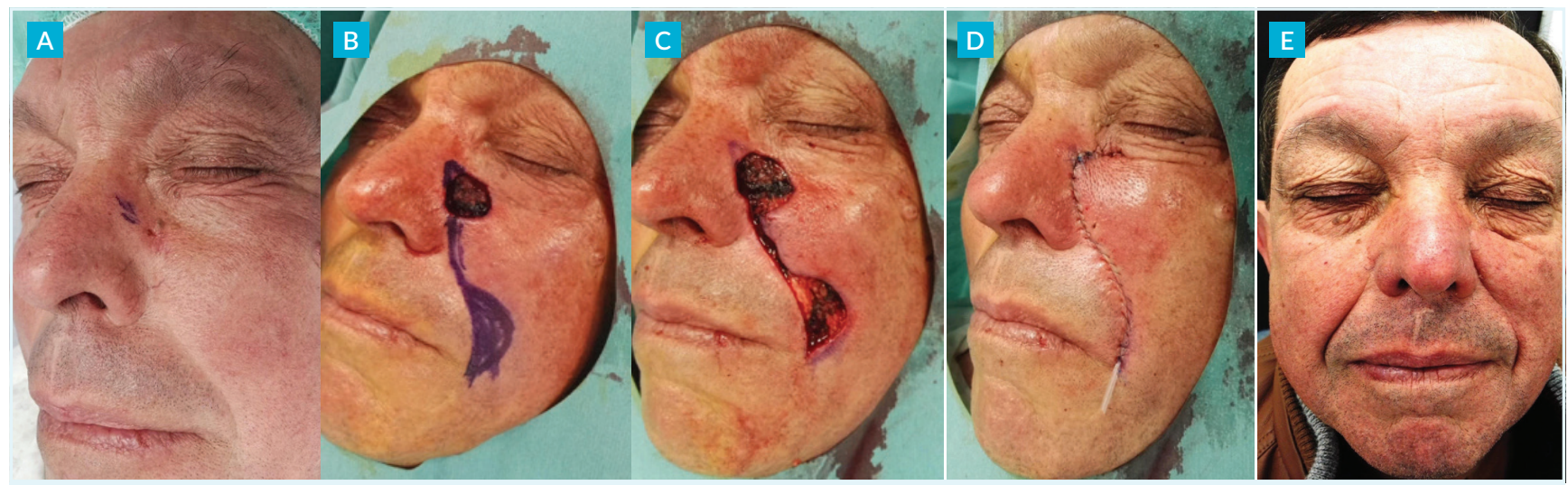

FIGURA 2. Carcinoma basocelular na região malar súpero-medial esquerda (a). Retalho de rotação súpero-medial projectado e dissecado ao longo da prega nasogeniana (b e c); distância entre o crescente e o defeito é superior à altura deste último (b e c). Resultado imediato (d). Resultado estético bastante aceitável após oito semanas, sem ectrópio cicatricial (e).
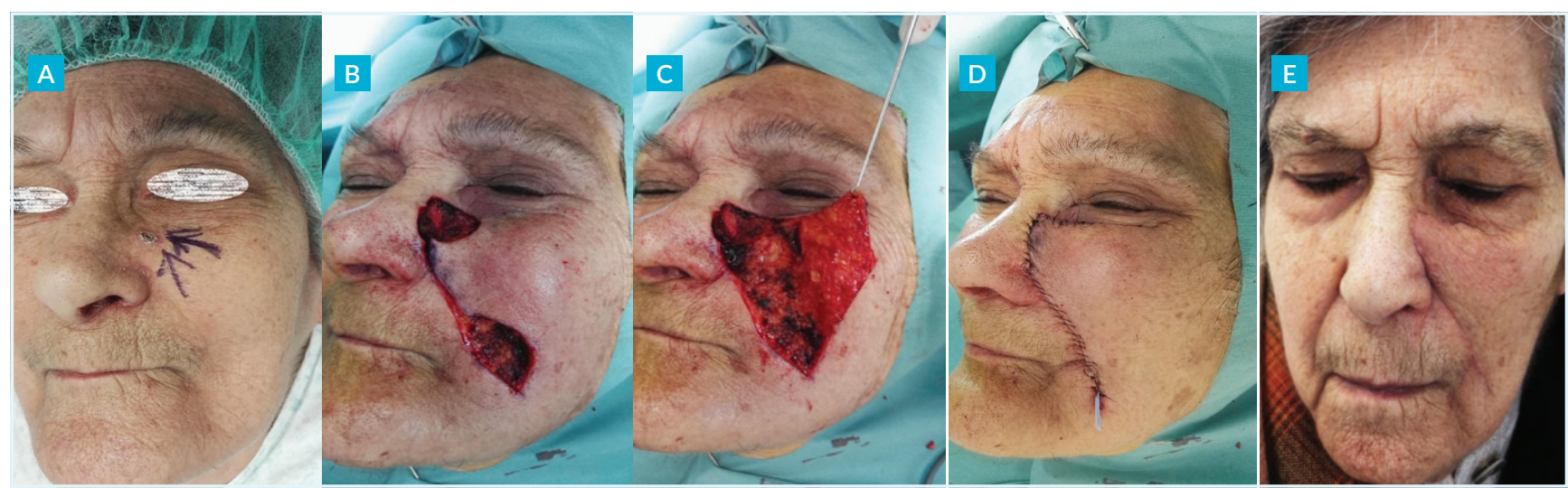

FIGURA 3. Carcinoma basocelular na região malar súpero-medial esquerda (a). Defeito cirúrgico envolvendo a pele palpebral ínfero-medial e retalho de rotação súpero-medial dissecado ao longo da prega nasogeniana (b); distância entre o crescente e o defeito é superior à altura deste último (b). Retalho dissecado e levantado após descolamento no plano do tecido adiposo (c). Resultado imediato com pele palpebral adaptada paralelamente às linhas de tensão (d). Resultado estético bastante aceitável após oito semanas, sem ectrópio cicatricial (e).

7. Excisão de pele redundante ao longo das linhas de tensão cutânea, com a pálpebra em estiramento máximo (doente olhando para cima com a boca aberta).

Foi instituída profilaxia antibiótica com clindamicina oral 600 mg, dose única, no pós-operatório. Com o intuito de evitar hemorragia e hematomas, foi feita hemostase ri- gorosa, e foram colocados drenos passivos por 48 horas (Fig.s 1d, 2d e 3d). O encerramento interno foi realizado com fio de sutura absorvível, de poliglactina (Vicryl ${ }^{\top M}$, Ethicon Inc.), e externo com não absorvível de poliamida (Ethilon ${ }^{\mathrm{TM}}$, Ethicon Inc.). Estes últimos foram removidos ao oitavo dia pós-operatório. 
TABELA 1. Três casos de carcinoma basocelular.

\begin{tabular}{|c|c|c|c|c|c|c|c|}
\hline Caso & $\begin{array}{l}\text { Sexo/ } \\
\text { Idade }\end{array}$ & Tumor & $\begin{array}{l}\text { Evolução } \\
\text { (meses) }\end{array}$ & $\begin{array}{l}\text { Localização } \\
\text { tumoral }\end{array}$ & $\begin{array}{l}\text { Diâmetro } \\
\text { tumoral } \\
(\mathrm{mm})\end{array}$ & $\begin{array}{c}\text { Extensão do defeito } \\
\text { cirúrgico }\end{array}$ & $\begin{array}{l}\text { Diâmetro } \\
\text { do defeito } \\
\text { cirúrgico } \\
\text { (mm) }\end{array}$ \\
\hline $\begin{array}{c}1 \\
\text { (Fig. 1) }\end{array}$ & $\begin{array}{l}\text { Masculino } \\
\quad / 71\end{array}$ & $\begin{array}{l}\text { Carcinoma } \\
\text { basocelular }\end{array}$ & Desconhecida & $\begin{array}{c}\text { Malar súpero-medial } \\
\text { e palpebral inferior } \\
\text { medial direito }\end{array}$ & 12 & $\begin{array}{l}\text { Malar súpero-medial } \\
\text { epalpebral inferior } \\
\text { medial direito }\end{array}$ & 22 \\
\hline $\begin{array}{c}2 \\
\text { (Fig. 2) }\end{array}$ & $\begin{array}{l}\text { Masculino } \\
\quad / 70\end{array}$ & $\begin{array}{l}\text { Carcinoma } \\
\text { basocelular }\end{array}$ & 12 & $\begin{array}{c}\text { Malar súpero-medial } \\
\text { esquerda }\end{array}$ & 10 & $\begin{array}{c}\text { Malar súpero-medial } \\
\text { esquerdo }\end{array}$ & 20 \\
\hline $\begin{array}{c}3 \\
\text { (Fig. 3) }\end{array}$ & $\begin{array}{l}\text { Feminino } \\
\text { /81 }\end{array}$ & $\begin{array}{l}\text { Carcinoma } \\
\text { basocelular }\end{array}$ & Desconhecida & $\begin{array}{c}\text { Malar súpero-medial } \\
\text { esquerda }\end{array}$ & 10 & $\begin{array}{c}\text { Malar súpero-medial } \\
\text { e palpebral inferior } \\
\text { medial esquerdo }\end{array}$ & 20 \\
\hline
\end{tabular}

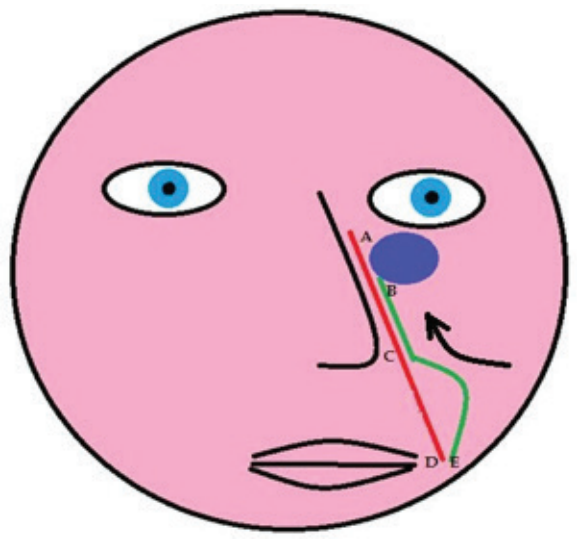

FIGURA 4. Representação esquemática do retalho de rotação súpero-medial. Distância $A B$ é a altura do defeito cirúrgico. Distância $\mathrm{BC}$ é a distância entre o defeito e o crescente. $\mathrm{BC} \geq \mathrm{AB}$. Distância da linha vermelha (AD) deve igualar a da linha verde (BE). CE - CD $\geq A B$. Seta indica o sentido de rotação/avanço superior e medial do retalho.

\section{RESULTADOS}

O diâmetro médio dos defeitos cirúrgicos foi de $21 \mathrm{~mm}$ (22 mm no caso 1 e 20 mm nos casos 2 e 3) (Tabela 1 e Fig.s 1b, 2b e 3b). Não se registaram complicações no pós-operatório imediato ou tardio, tais como hemorragia, isquemia, necrose, deiscência, infeção ou hematoma. Os resultados morfológicos e funcionais foram aceitáveis, seis (Fig. 1e) e oito semanas depois (Fig.s 2e e 3e). Em nenhum dos casos ocorreu ectrópio cicatricial. Os doentes permanecem em seguimento regular e sem recidiva aos 12 meses.

\section{DISCUSSÃO}

O RRSM é um retalho malar local, randomizado, crescêntico, predominantemente de rotação e com grau ligeiro a moderado de avanço. Foi concebido por Hussain et al, ${ }^{1}$ para o encerramento de defeitos cirúrgicos de média e grande dimensão, localizados na região malar súpero-medial e pele palpebral inferior. Em termos técnicos, o RRSM é uma modificação do retalho de Imre original, um procedimento inicialmente desenhado e executado pelo oftalmologista Joseph Imre, Jr., ${ }^{2}$ para reconstrução da mesma região. A incisão malar central e o triângulo de Burrow distal, presentes neste último, são substituídos no RRSM por uma incisão na prega nasogeniana e por um crescente deslizante, respetivamente, com melhores resultados cosméticos.

No trabalho apresentado por Hussain et al, ${ }^{1}$ o diâmetro médio (maior eixo) dos defeitos cirúrgicos foi de $20 \mathrm{~mm}$, um valor quase idêntico ao presente neste estudo. É de salientar que esta técnica não está indicada nos casos em que o defeito se estende para além da linha média pupilar, em particular na pálpebra inferior, devido ao risco elevado de ectrópio cicatricial; está também contraindicada nos doentes com défice e/ou limitação marcada da mobilidade da pele malar e/ou palpebral causada por cicatrizes prévias (cirurgia, queimaduras, radioterapia, tratamentos estéticos) e/ou patologias inflamatórias (esclerose sistémica, lúpus eritematoso cutâneo crónico, entre outros).

A execução técnica correta do RRSM é essencial para um bom resultado funcional e morfológico. A incisão ao longo da prega nasogeniana coloca a cicatriz na junção de duas subunidades estéticas, permitindo a camuflagem da mesma. $\bigcirc$ crescente na extremidade distal do retalho, quando executado de acordo com as regras mencionadas anteriormente, permite aumentar o comprimento do retalho e obter pele suficiente para encerrar o defeito e servir de suporte da pálpebra inferior. Para isso, torna-se crucial o descolamento cutâneo amplo e cauteloso ao nível do tecido adiposo, assim como a sutura do retalho a partir do limite inferior. Uma ou duas suturas de ancoragem da ponta do retalho no periósteo periorbitário são fundamentais e minimizam o risco de ectrópio. A adaptação palpebral deve constituir o último procedimento, devendo-se evitar remoção cutânea excessiva e, sempre que possível, suturas verticais.

Outros procedimentos cirúrgicos para o encerramento 
dos defeitos cirúrgicos das regiões malar medial superior e pálpebra inferior incluem o retalho de rotação de Tinzel modificado, ${ }^{3,4}$ o retalho de rotação de Mostardé, ${ }^{4}$ o retalho de avanço de pedículo subcutâneo, ,,6 o retalho "em machado" de Emmett, a a combinação dos retalhos de avanço pediculado e glabelar, ${ }^{8}$ o retalho malar de avanço isolado ou combinado com o retalho glabelar de transposição ou de avanço, o enxerto de pele total e a cicatrização por segunda intenção.

\section{CONCLUSÃO}

O RRSM revelou-se uma técnica segura e eficaz no encerramento dos defeitos cirúrgicos das regiões malar medial superior e palpebral inferior, com bons resultados estéticos e funcionais. Como tal, constitui uma válida opção cirúrgica a ser considerada pelos cirurgiões na reconstrução desta região anatómica.

\section{AGRADECIMENTOS/ ACKNOWLEDGMENTS}

Serviço de Anatomia Patológica e equipas de enfermagem e assistente operacional do Bloco Operatório Central e da Consulta Externa, Hospital de Vila Franca de Xira.

APRESENTAÇÕES/PRESENTATIONS: Comunicação oral no $5^{\circ}$ Curso de Cirurgia e Cosmética Dermatológica, Coimbra, 13 e 14 de outubro 2017.

CONFLITOS DE INTERESSE: Os autores declaram não ter qualquer conflito de interesse na realização do presente trabalho.

FONTES DE FINANCIAMENTO: Não houve qualquer fonte de financiamento na realização do presente trabalho.

CONFIDENCIALIDADE DOS DADOS: Os autores declaram ter seguido os protocolos da sua instituição acerca da publicação dos dados de doentes.

PROTEÇÃO DE PESSOAS E ANIMAIS: Os autores declaram que os procedimentos seguidos na elaboração do presente trabalho estão em conformidade com as normas das comissões de investigação clínica e de ética, bem como da declaração de Helsínquia e da Associação Médica Mundial.

\section{CONSENTIMENTO DOS DOENTES: Obtido.}

CONFLICTS OF INTEREST: The authors declare that they have no conflicts of interest.

FINANCIAL SUPPORT: This work has not received any contribution, grant or scholarship.
CONFIDENTIALITY OF DATA: The authors declare that they have followed the protocols of their work center on the publication of data from patients.

PROTECTION OF HUMAN AND ANIMAL SUBJECTS: The authors declare that the procedures followed were in accordance with the regulations of the relevant clinical research ethics committee and with those of the Code of Ethics of the World Medical Association (Declaration of Helsinki).

PATIENT CONSENT: Obtained.

\section{REFERÊNCIAS}

1. Hussain W, Tan E, Salmon PJ. Inferiorly based crescentic "sliding" cheek flaps for the reconstruction of paranasal surgical defects. Dermatol Surg. 2012;38:249-55.

2. Metzger JT. Joseph Imre Jr. and the Imre flap. Plast Reconstr Surg Transplant Bull. 1959;23:501-9.

3. Tenzel RR. Reconstruction of the central one half of an eyelid. Arch Ophthalmol 1975;93:125-26.

4. Russo F, Linares M, Iglesias ME, Martínez-Amo JL, Cabo F, Tercedor J, et al. Reconstruction Techniques of Choice for the Facial Cosmetic Units. Actas Dermosifiliogr. 2017;108:729-37.

5. Laitano FF, Teixeira LF, Siqueira EJ, Alvarez GS, Martins PE, de Oliveira MP. Use of skin flaps for nasal reconstruction after neoplastic resection. Rev Bras Cir Plást. 2012;27:217-22.

6. Matos D, Goulão J. Retalho nasogeniano V-Y de avanço: duas variantes úteis na reconstrução nasal. Rev Soc Port Dermatol Venereol. 2014;72:525-9.

7. Dölen UC, Uğur K. Innovation in the planning of $V-Y$ rotation advancement flaps: A template for flap design. Arch Plast Surg. 2018;45:85-8

8. Matsuda H, Takahashi Y, Ichinose A, Miyazaki H, Kakizaki H. Combination of nasolabial $\mathrm{V}-\mathrm{Y}$ advancement flap and glabellar subcutaneous pedicled flap for reconstruction of medial canthal defect. Case Rep Ophthalmol. 2014;5:50-3. 